\title{
A cluster-randomized trial determining the efficacy of caterpillar cereal as a locally available and sustainable complementary food to prevent stunting and anaemia
}

\author{
Melissa Bauserman ${ }^{1,2, *}$, Adrien Lokangaka ${ }^{3}$, Justin Gado ${ }^{3}$, Kelly Close ${ }^{4}$, \\ Dennis Wallace ${ }^{4}$, Kule-Koto Kodondi ${ }^{5}$, Antoinette Tshefu ${ }^{3}$ and Carl Bose ${ }^{1}$ \\ 'Department of Pediatrics, Division of Neonatal-Perinatal Medicine, School of Medicine, University of North Carolina \\ at Chapel Hill, 101 Manning Drive, CB\#7596, Chapel Hill, NC 27599-7596, USA: '2Department of Nutrition, \\ University of North Carolina Gillings School of Global Public Health, Chapel Hill, NC, USA: ${ }^{3}$ Kinshasa School of \\ Public Health, Kinshasa, Democratic Republic of Congo: ${ }^{4}$ RTI International, Research Triangle Park, NC, USA: \\ ${ }^{5}$ Department of Pharmacy, University of Kinshasa, Kinshasa, Democratic Republic of Congo
}

Submitted 15 August 2014: Final revision received 27 November 2014: Accepted 22 December 2014: First published online 29 January 2015

\begin{abstract}
Objective: We conducted a cluster-randomized controlled trial to assess the efficacy of a cereal made from caterpillars, a micronutrient-rich, locally available alternative animal-source food, on reducing stunting and anaemia in infants in the Democratic Republic of Congo.

Design: Six-month-old infants were cluster randomized to receive either caterpillar cereal daily until 18 months of age or the usual diet. At 18 months of age, anthropometric measurements and biological samples were collected.

Setting: The rural Equateur Province in the Democratic Republic of Congo.

Subjects: One hundred and seventy-five infants followed from 6 to 18 months of age. Results: Stunting was common at 6 months (35\%) and the prevalence increased until 18 months (69\%). There was no difference in stunting prevalence at 18 months between the intervention and control groups $(67 \% v .71 \%, P=0.69)$. Infants in the cereal group had higher $\mathrm{Hb}$ concentration than infants in the control group $(10 \cdot 7 v \cdot 10 \cdot 1 \mathrm{~g} / \mathrm{dl}, P=0.03)$ and fewer were anaemic $(26 v .50 \%, P=0.006)$, although there was no difference in estimates of body Fe stores $(6.7 v .7 .2 \mathrm{mg} / \mathrm{kg}$ body weight, $P=0 \cdot 44$ ).

Conclusions: Supplementation of complementary foods with caterpillar cereal did not reduce the prevalence of stunting at 18 months of age. However, infants who consumed caterpillar cereal had higher $\mathrm{Hb}$ concentration and fewer were anaemic, suggesting that caterpillar cereal might have some beneficial effect. The high prevalence of stunting at 6 months and the lack of response to this micronutrient-rich supplement suggest that factors other than dietary deficiencies also contribute to stunting.
\end{abstract}

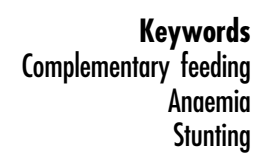

Micronutrient deficiency is a serious problem in most low-income countries, contributing to $3 \cdot 1$ million deaths annually in children younger than 5 years $^{(1,2)}$. Stunting is a major consequence of malnutrition and is associated with increased mortality, poor cognitive and motor development, impaired physical performance, reduced income in adulthood and lower birth weight in offspring ${ }^{(3-5)}$. Stunting is a major global health problem that disproportionately affects populations living in low-income countries, including the Democratic Republic of Congo (DRC), where more than $46 \%$ of all children under 5 years of age are stunted ${ }^{(6)}$.

If childhood stunting is not modified by 2 years of age, impairment in growth may be irreversible and many of the associated consequences may be inevitable ${ }^{(7)}$. In this age group, inadequate nutrient intake resulting from the consumption of micronutrient-deficient complementary foods might contribute to the prevalence of stunting in lowincome countries. In the DRC, nutrient intake is probably adequate during the first 6 months of life when exclusive breast-feeding is practised $^{(8)}$; however, complementary foods provided thereafter are typically starch-based cereals or gruels. These foods might provide sufficient energy but do not provide adequate micronutrients. Authoritative guidelines on optimal complementary feeding recommend the daily intake of animal-source foods because it is not possible to achieve adequate intakes of 
the so-called 'problem nutrients', specifically $\mathrm{Fe}$ and $\mathrm{Zn}$, with plant-based diets alone ${ }^{(9-11)}$. This strategy has limited applicability in many low-income countries where animalsource foods are not accessible or affordable.

Insects have played an important role in the history of human nutrition in Africa, Asia and Latin America and continue to be a critical element of modern diets in Central Africa $^{(12,13)}$. For example, in most areas of the DRC, caterpillars are a staple in the diet, in contrast to meat, which is rarely consumed. A caterpillar cereal, made from ingredients that are locally available in the DRC, has an appropriate micronutrient content for complementary feeding and has been found to be acceptable by mothers and children ${ }^{(14)}$.

The primary goal of the present study was to determine the effect of feeding caterpillar cereal to 6-month-old infants for 12 months on the prevalence of stunting at 18 months of age. We hypothesized that $25 \%$ fewer infants consuming micronutrient-rich caterpillar cereal would be stunted compared with infants consuming the usual Congolese diet. We also compared the effects of caterpillar cereal consumption on anaemia and Fe status as secondary outcomes.

\section{Experimental methods}

\section{Study design and setting}

We conducted a cluster-randomized controlled trial in the rural Equateur Province of the DRC between 2010 and 2012 to compare a cohort of infants who consumed caterpillar cereal daily (intervention group) with a similar cohort of infants who consumed their usual diet (control group). We used the cluster randomization approach to avoid cross-contamination among study participants in different study arms. We selected eight communities (clusters) that were randomized at the community level to the intervention or control group. If baseline estimates of stunting rates were known, we randomized pairs of communities with similar stunting rates to alternative study arms. From previous pilot studies, four communities had stunting rates of $49-73 \%$ among 18 -month-old infants. In communities in which estimates of baseline stunting rates were unavailable, we randomly assigned communities to control and intervention arms in a $1: 1$ ratio by a computer-generated sequence performed by the central data coordinating centre. The clusters were geographically distant from one another in order to minimize the risk of spill-over of the intervention to the control group.

From a log of all births within the community, we used computer-generated, random lists of infants within each cluster to recruit and screen potential participants. We recruited 5-month-old infants who were exclusively breastfed and whose mothers intended to continue breast-feeding for the first year of life. We excluded infants who were likely to receive free or subsidized complementary foods or formula, families likely to relocate during the study period, infants of multiple birth and infants with known congenital anomalies or neurological deficits. All participants were assigned to a study group based on the cluster in which they lived.

We calculated a sample size of 100 infants in each group to detect an absolute reduction of $25 \%$ in the prevalence of stunting at 18 months in the intervention group compared with the control group. We set a statistical power of $80 \%$ using a two-tailed test and a rate of $5 \%$ error. We estimated an attrition rate of $10 \%$ and assumed an intra-cluster correlation coefficient of 0.05 (to account for correlation of outcomes within clusters). Therefore we recruited 110 infants in each group for a final sample size of 220 infants in eight clusters.

The study was conducted according to the guidelines laid down in the Declaration of Helsinki and all procedures involving human subjects were approved by the Institutional Review Boards at the University of North Carolina and the Kinshasa School of Public Health. Written informed consent was obtained from a parent of each infant. We registered the study through ClinicalTrials.gov (NCT01282788).

\section{Intervention}

We supplied participants in the intervention group with a daily portion of pre-packaged caterpillar cereal. All cereal was produced, weighed and packaged into $30 \mathrm{~g}$ or $45 \mathrm{~g}$ hermetically sealed sachets in a laboratory at the University of Kinshasa. We transported the sachets to the study communities, where they were distributed to participants weekly. We supplied infants 6-12 months of age with a $30 \mathrm{~g}$ portion of caterpillar cereal daily, and we supplied infants $12-18$ months with a $45 \mathrm{~g}$ portion. A $30 \mathrm{~g}$ portion of caterpillar cereal provided approximately $552 \mathrm{~kJ}$ (132 kcal), $6.9 \mathrm{~g}$ protein, $6.3 \mathrm{~g}$ fat, $12 \mathrm{~g}$ carbohydrate, $3.8 \mathrm{mg} \mathrm{Fe}$ and $3.8 \mathrm{mg} \mathrm{Zn}$; and a $45 \mathrm{~g}$ portion of caterpillar cereal provided approximately $828 \mathrm{~kJ}$ (198 kcal), $10.3 \mathrm{~g}$ protein, $9.4 \mathrm{~g}$ fat, $18 \mathrm{~g}$ carbohydrate, $5.7 \mathrm{mg} \mathrm{Fe}$ and $5.6 \mathrm{mg}$ $\mathrm{Zn}^{(14)}$. We intended for the cereal to supplement other usual dietary intake. Infants in the control group consumed their usual diets.

Mothers of infants in both groups received educational messages about complementary feeding including instructions about the importance of feeding thickened gruels, offering complementary foods more than three times daily, optimizing variety in complementary foods, hand washing and using boiled water in food preparation. Established community health workers delivered these messages at weekly home visits.

\section{Data collection}

We collected baseline information for mothers at the time of enrolment including demographic information and socio-economic status. We interviewed the mother about her current health status, history of infectious diseases and 
previous obstetric history. We measured maternal height and weight at the infant's 6-month visit. We interviewed the mother about the health status of the infant including a history of prematurity and birth weight.

\section{Outcome measures}

\section{Feeding and growth}

We monitored compliance with the feeding regimen through a combination of scheduled home visits (daily for weeks 1-3 of participation, three times weekly for weeks 4-12 and weekly for weeks 13-52) and unscheduled home visits (once per month). We estimated the consumption of cereal from maternal report and the collection of unused food sachets. At 6, 9, 12 and 18 months, study personnel collected a $24 \mathrm{~h}$ dietary recall to determine the content and quality of other foods that were consumed by the infant. We assessed infant feeding practices using the Infant and Child Feeding Index (ICFI) at 6, 9, 12 and 18 months $^{(15,16)}$. Higher ICFI scores reflect more positive feeding practices with regard to breast-feeding, meal frequency and food diversity.

We collected anthropometric measurements on infants at 6, 9, 12 and 18 months of age. Study personnel who were blinded to group assignment performed measurements in a standardized manner.

\section{Anaemia and Fe status}

We measured blood indices of Fe status at 18 months in a convenience sample of 133 infants. The convenience sample was chosen among the first sixty-five to seventy infants in each group who presented for the final evaluation and consented to have blood collected for analysis. $\mathrm{Hb}$ was measured using HemoCue Hb Systems (Angelholm, Sweden). We defined anaemia as Hb concentration less than or equal to $10 \mathrm{~g} / \mathrm{dl}^{(17)}$. For the measurement of serum proteins, serum was separated by centrifugation within $1 \mathrm{~h}$ of collection and stored at $-20^{\circ} \mathrm{C}$ for up to 2 months, then stored at $-80^{\circ} \mathrm{C}$ until shipment for analyses. Serum ferritin, C-reactive protein (CRP) and soluble transferrin receptor were measured using standard laboratory techniques in a central laboratory (VitA Iron Lab, Wilstaett Germany) ${ }^{(18-20)}$.

We estimated body Fe stores using the method developed by Cook et al., as follows: body Fe stores $(\mathrm{mg} / \mathrm{kg})=$ - $[\log ($ serum transferrin receptor/serum ferritin ratio) $2 \cdot 8229] / 0 \cdot 1207^{(21)}$. Positive values indicate $\mathrm{Fe}$ stores in surplus and negative values indicate tissue Fe deficiency ${ }^{(21)}$. This method has been used in other Fe supplementation trials to determine Fe absorption. We also examined ferritin concentration as an indicator of a deficiency of Fe stores. Since ferritin is an acute-phase reactant that is elevated in the presence of infection or inflammation ${ }^{(22)}$, we defined Fe-deficiency anaemia as $\mathrm{Hb}$ concentration $\leq 10 \mathrm{~g} / \mathrm{dl}$ and ferritin concentration $<12 \mu \mathrm{g} / \mathrm{l}$, excluding infants with CRP concentration $>5 \mathrm{mg} /$.

\section{Infectious morbidity}

During the weekly home visits, we collected information about infectious illnesses. We asked mothers to recall from the previous week if the infant experienced signs or symptoms of respiratory infections (fever, cough, fast breathing, lower chest wall in-drawing), diarrhoea (more than three watery stools per day or stool frequency increased from usual) or malaria (confirmed by a health worker, by symptoms or blood test).

\section{Statistical analyses}

We compared characteristics between groups at baseline, including sex, socio-economic status, rates of exclusive breast-feeding (by maternal report) at 6 months, birth weight (by maternal report), maternal age and education, maternal health history and parity, using simple mixed models adjusting for clusters. To compare anthropometric outcomes, we calculated mean $Z$-scores at 6, 9, 12 and 18 months for length-for-age, weight-for-age and weight-for-length, determined from WHO growth standards ${ }^{(23)}$. We used modelling approaches to evaluate treatment-group differences in baseline variables, anthropometric measurements and primary and secondary outcomes, using generalized estimating equation extensions (GEE) of robust Poisson regression models for categorical measures and linear mixed models for continuous measures to account for the correlation of participants induced by cluster randomization and for the correlation of the measurements within individuals across time for the longitudinal anthropometric measures. Differences in mean biomarker concentration were compared using linear mixed models. We considered $P<0.05$ to be significant with no adjustment for multiple comparisons. We analysed data using the SAS statistical software package version 9.3 and present results as means and standard deviations unless otherwise indicated.

\section{Results}

We screened 227 infants from eight communities and enrolled 222; 111 infants were enrolled in clusters randomized to the cereal group and 111 infants were enrolled in clusters randomized to the control group (Fig. 1). Of the 222 infants who were enrolled in the trial, seven (3\%) died, thirty-eight ( $17 \%)$ relocated and one $(<1 \%)$ withdrew from the study. In the cereal group, ninety-one (82\%) infants completed the trial, and in the control group eighty-four $(76 \%)$ infants completed the trial. Of the infants who completed the trial, we obtained anthropometric data on eighty-one infants in the cereal group and eighty-two infants in the control group. Equipment to accurately measure length and weight were unavailable at the time of study completion for a proportion of the infants ( $11 \%$ in the cereal group and $2 \%$ of the control group). We collected blood specimens for biomarker analysis from 133 infants chosen by convenience sample. 


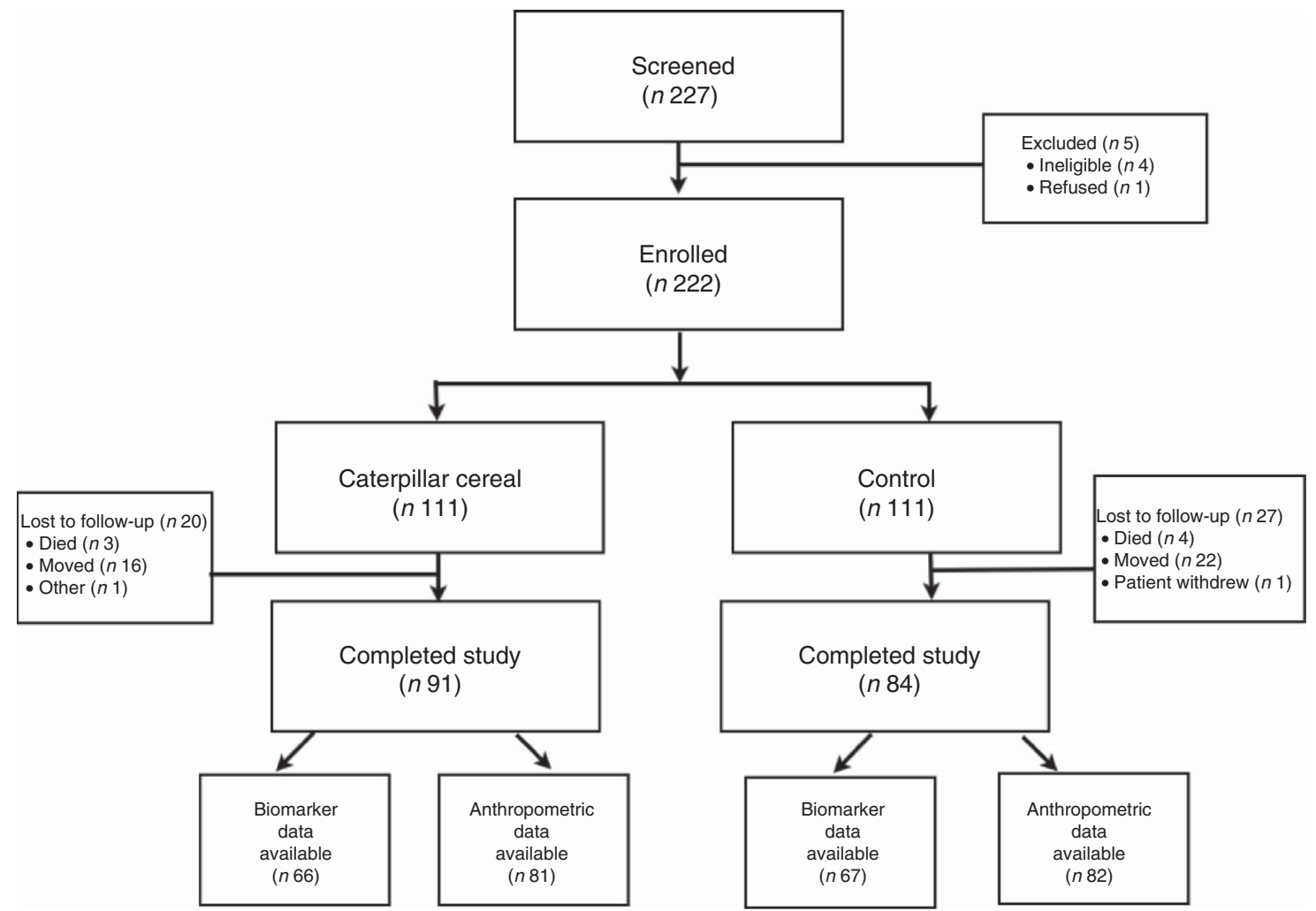

Fig. 1 CONSORT (Consolidated Standards Of Reporting Trials) flow diagram of participants in the present cluster-randomized controlled trial

Table 1 Baseline characteristics of participants, rural Equateur Province, Democratic Republic of Congo, 2010-2012

\begin{tabular}{|c|c|c|c|c|c|}
\hline & \multicolumn{2}{|c|}{ Caterpillar cereal group ( $n$ 111) } & \multicolumn{2}{|c|}{ Control group ( $n$ 111) } & \multirow[b]{2}{*}{$P$ value $\dagger$} \\
\hline & Mean or $n$ & SD or $\%$ & Mean or $n$ & SD or $\%$ & \\
\hline \multicolumn{6}{|l|}{ Maternal characteristics } \\
\hline Maternal height $(\mathrm{cm})$ & 158 & $7 \cdot 0$ & 155 & 8.4 & $0.01^{*}$ \\
\hline Maternal weight $(\mathrm{kg})$ & $52 \cdot 0$ & $7 \cdot 4$ & $51 \cdot 4$ & $8 \cdot 7$ & 0.82 \\
\hline Maternal BMI $\left(\mathrm{kg} / \mathrm{m}^{2}\right)$ & $21 \cdot 0$ & $3 \cdot 4$ & $21 \cdot 4$ & $3 \cdot 2$ & 0.72 \\
\hline Mother works for pay (yes), $n$ and $\%$ & 2 & 1.8 & 1 & 0.9 & 0.44 \\
\hline Highest level of formal education the mother has completed (years) & $3 \cdot 8$ & $3 \cdot 2$ & 3.5 & $3 \cdot 2$ & 0.43 \\
\hline Highest level of formal education the father has completed (years) & $8 \cdot 2$ & $3 \cdot 2$ & $7 \cdot 1$ & $3 \cdot 8$ & $0.02^{*}$ \\
\hline Number of pregnancies & 3.7 & $2 \cdot 1$ & $4 \cdot 1$ & $2 \cdot 2$ & 0.15 \\
\hline Number of children & $2 \cdot 9$ & $1 \cdot 7$ & $3 \cdot 0$ & 1.6 & 0.62 \\
\hline \multicolumn{6}{|l|}{ Infant characteristics } \\
\hline Male, $n$ and \% & 56 & 50.5 & 57 & $51 \cdot 4$ & 0.89 \\
\hline Birth weight (g) & 3175 & 518 & 3377 & 529 & $0.005^{*}$ \\
\hline Born prematurely, $n$ and $\%$ & 2 & $1 \cdot 8$ & 1 & 0.9 & 0.62 \\
\hline Exclusively breast-fed at 6 months, $n$ and \% & 88 & $79 \cdot 3$ & 80 & $72 \cdot 1$ & 0.84 \\
\hline
\end{tabular}

Data are presented as mean and SD, except where shown.

*Denotes statistical significance.

$\dagger P$ value calculated using a robust Poisson regression model for categorical outcomes and a linear mixed model for continuous outcomes utilizing a GEE (generalized estimating equation extensions) approach with a robust variance estimator to adjust for clusters.

The two groups were similar in baseline characteristics except for taller mean maternal height $(158 v .155 \mathrm{~cm}$, $P=0 \cdot 01)$, more mean years of paternal education (8.2 $v$. $7 \cdot 1$ years, $P=0 \cdot 02)$ and lower mean birth weight (3175 $v$. $3377 \mathrm{~g}, P=0.005$ ) in the cereal group (Table 1). Rates of reported exclusive breast-feeding at 6 months were similar ( $79 \%$ in the cereal group and $72 \%$ in the control group). There were no differences in baseline characteristics between the participants who completed the study and those who were lost to follow-up (data not shown).

\section{Feeding and growth}

In the cereal group, sixty-six (62\%) infants consumed $>90 \%$ of the cereal and ninety-six (90\%) consumed $>70 \%$. Of the 40800 infant-days in the trial, we recorded 771 (1.8\%) days during which no study food was 
Table 2 Anthropometric data at baseline (6 months), during (9 and 12 months) and at the end (18 months) of the cluster-randomized controlled trial assessing the efficacy of caterpillar cereal on infant stunting and anaemia, rural Equateur Province, Democratic Republic of Congo, 2010-2012

\begin{tabular}{|c|c|c|c|c|c|c|c|}
\hline & \multicolumn{3}{|c|}{ Caterpillar cereal group } & \multicolumn{3}{|c|}{ Control group } & \multirow[b]{2}{*}{$P$ value } \\
\hline & $n$ & $n$ or Mean & $\%$ or SD & $n$ & $n$ or Mean & $\%$ or SD & \\
\hline \multicolumn{8}{|l|}{ Stunting prevalence (LAZ <-2), $n$ and $\%$} \\
\hline 6 months & 111 & 40 & 36 & 111 & 37 & 33 & 0.71 \\
\hline 9 months & 97 & 41 & 42 & 103 & 46 & 45 & 0.90 \\
\hline 12 months & 93 & 44 & 47 & 99 & 45 & 46 & 0.82 \\
\hline 18 months & 81 & 54 & 67 & 82 & 58 & 71 & 0.69 \\
\hline \multicolumn{8}{|l|}{ LAZ, mean and SD } \\
\hline 6 months & 111 & -1.5 & 1.4 & 111 & -1.5 & 1.4 & 0.71 \\
\hline 9 months & 97 & $-1 \cdot 7$ & $1 \cdot 2$ & 103 & $-1 \cdot 8$ & 1.5 & 0.76 \\
\hline 12 months & 93 & -1.9 & $1 \cdot 2$ & 99 & $-2 \cdot 0$ & 1.5 & 0.67 \\
\hline 18 months & 81 & $-2 \cdot 5$ & $1 \cdot 2$ & 82 & $-2 \cdot 6$ & $1 \cdot 7$ & 0.54 \\
\hline Linear growth velocity ( $\mathrm{cm} /$ month), mean and SD & 79 & 0.9 & 0.3 & 81 & 0.9 & 0.2 & 0.76 \\
\hline \multicolumn{8}{|l|}{ Wasting prevalence (WLZ $<-2$ ), $n$ and $\%$} \\
\hline 6 months & 111 & 10 & 9 & 110 & 14 & 13 & 0.61 \\
\hline 9 months & 97 & 9 & 9 & 102 & 5 & 5 & 0.37 \\
\hline 12 months & 91 & 6 & 7 & 94 & 7 & 7 & 0.91 \\
\hline 18 months & 80 & 6 & 8 & 80 & 8 & 10 & 0.60 \\
\hline \multicolumn{8}{|l|}{ WAZ, mean and SD } \\
\hline 6 months & 111 & $-1 \cdot 0$ & 1.4 & 110 & $-1 \cdot 2$ & 1.4 & 0.20 \\
\hline 9 months & 97 & $-1 \cdot 2$ & 1.4 & 102 & -1.0 & 1.2 & 0.32 \\
\hline 12 months & 91 & $-1 \cdot 2$ & 1.1 & 94 & $-1 \cdot 1$ & 1.3 & 0.47 \\
\hline 18 months & 80 & -1.5 & 1.2 & 82 & -1.3 & 1.2 & 0.40 \\
\hline \multicolumn{8}{|l|}{ WLZ, mean and SD } \\
\hline 6 months & 111 & 0.0 & 1.5 & 110 & -0.2 & $1 \cdot 8$ & 0.22 \\
\hline 9 months & 97 & -0.2 & 1.4 & 102 & 0.1 & 1.2 & 0.07 \\
\hline 12 months & 91 & -0.2 & $1 \cdot 1$ & 94 & 0.1 & 1.4 & 0.11 \\
\hline 18 months & 79 & -0.4 & 1.3 & 80 & -0.2 & 1.4 & 0.37 \\
\hline
\end{tabular}

LAZ, length-for-age Z-score; WLZ, weight-for-length Z-score; WAZ, weight-for-age Z-score.

$\dagger P$ value calculated using longitudinal linear mixed models (for the categorical measures) and robust Poisson generalized linear model extensions (for binary measures) utilizing a GEE (generalized estimating equation extensions) approach with a robust variance estimator to adjust for clusters and correlation within participants across the longitudinal measures.

consumed. During these days, lack of consumption of study food was attributable to illness (7\%), lack of time to feed the study food (3\%), infant's apparent dislike of food (3\%) and infant's lack of hunger (0.1\%).

The percentage of women who breast-fed their infants was high throughout the trial (>96\%) and did not differ between the groups at any assessment point (6, 9, 12 and 18 months). There was no difference in ICFI between the groups at 6 months and 18 months. At 9 months, ICFI was higher in the control group $(5 \cdot 8 v \cdot 5 \cdot 2, P=0.01)$ and at 12 months, ICFI was higher in the cereal group $(6.1 v .5 \cdot 2, P<0 \cdot 001)$. Oral micronutrient supplementation was rare at 6 months $(<1 \%$ in both groups). At 9 months more infants in the cereal group consumed multivitamins $(23 \%$ v. $0 \%, P<0.001)$, and at 18 months, fewer infants in the cereal group consumed multivitamins ( $5 \% v .27 \%, P<0.001)$. There was no difference in multivitamin use at 12 months $(29 \%$ in the cereal group $v .18 \%$ in the control group, $P=0.08)$.

We observed a high prevalence of stunting at 6 months of age in both groups (36\% in the cereal group $v .33 \%$ in the control group, $P=0 \cdot 71$; Table 2$)$. The percentage of infants who were stunted increased at each subsequent time point. There was no difference in the proportion of children who were stunted at 18 months of age between the cereal and control groups (67\% v. $71 \%, P=0.69)$.
Among the 163 participants who had length data at 18 months, twenty-nine out of eighty-one $(36 \%)$ in the cereal group and twenty-two out of eighty-two (27\%) in the control group were stunted at 6 months $(P=0 \cdot 26)$.

A regression model, controlling for cohort characteristics (parental education, employment, number of pregnancies/ children, maternal infectious morbidities, maternal anthropometry, prematurity, sex, exclusive breast-feeding, lengthfor-age $Z$-score at 6 months and ICFI at 6 months), showed no treatment effect on the proportion of infants who were stunted $(P=0.38)$. We did not include birth weight in the model because these data were not considered to be sufficiently reliable. Using bivariate analysis with adjustment for cluster effect, we found no difference in secondary outcomes at 18 months between the two groups: length-for-age Z-scores, linear growth velocity, weight-for-age $Z$-scores, prevalence of wasting and weight-for-length $Z$-scores (Table 2). The growth parameters were not significantly different between the two groups at any of the interval measurements.

\section{Anaemia and Fe status}

At 18 months of age, infants in the cereal group had higher $\mathrm{Hb}$ concentration than infants in the control group (10.7 $v$. $10 \cdot 1 \mathrm{~g} / \mathrm{dl}, P=0.03)$ and fewer were anaemic (26\% v. $50 \%$, 
Table 3 Biomarker data for a convenience sample of infants at 18 months of age following participation in the cluster-randomized controlled trial assessing the efficacy of caterpillar cereal on infant stunting and anaemia, rural Equateur Province, Democratic Republic of Congo, 2010-2012

\begin{tabular}{|c|c|c|c|c|c|c|c|}
\hline & \multicolumn{3}{|c|}{ Caterpillar cereal group } & \multicolumn{3}{|c|}{ Control group } & \multirow[b]{2}{*}{$P$ value- } \\
\hline & $n$ & Mean or $n$ & SD or $\%$ & $n$ & Mean or $n$ & SD or $\%$ & \\
\hline $\mathrm{Hb}(\mathrm{g} / \mathrm{dl})$ & 77 & $10 \cdot 7$ & 1.6 & 64 & $10 \cdot 1$ & 1.8 & $0.03^{*}$ \\
\hline Ferritin (ng/ml) & 66 & 145 & $97 \cdot 3$ & 67 & 187 & $116 \cdot 2$ & $0.03^{*}$ \\
\hline Transferrin receptor (mg/l) & 66 & 11.9 & $4 \cdot 1$ & 67 & 13.0 & $4 \cdot 8$ & 0.15 \\
\hline $\mathrm{CRP}(\mathrm{mg} / \mathrm{l})$ & 66 & $12 \cdot 9$ & $16 \cdot 4$ & 67 & $12 \cdot 0$ & $15 \cdot 7$ & 0.74 \\
\hline Body Fe stores (mg/kg body weight) & 66 & $6 \cdot 7$ & 3.3 & 67 & $7 \cdot 2$ & 4.0 & 0.44 \\
\hline Anaemic $(\mathrm{Hb} \leq 10 \mathrm{~g} / \mathrm{dl}), n$ and $\%$ & 77 & 20 & $26 \cdot 0$ & 64 & 32 & $50 \cdot 0$ & $0.006^{\star}$ \\
\hline
\end{tabular}

CRP, C-reactive protein.

Data are presented as mean and SD, except where shown.

*Denotes statistical significance.

$\dagger P$ value calculated using a linear mixed model utilizing a GEE (generalized estimating equation extensions) approach with a robust variance estimator to adjust for clusters.

$P=0.006$; Table 3). Transferrin receptor and body Fe stores did not differ between the two groups. The ferritin concentration was lower in the cereal group (145v. $187 \mathrm{ng} / \mathrm{dl}, P=0.03)$. Because some biomarkers of $\mathrm{Fe}$ deficiency, such as ferritin, are elevated in the presence of inflammation, we examined ferritin concentration separately in infants without inflammation by excluding infants with elevated CRP from the analysis. Twenty-nine infants in the cereal group and thirty-five infants in the control group had CRP concentration $>5 \mathrm{mg} / \mathrm{l}$. Using our a priori definition of Fe-deficiency anaemia, after excluding infants with CRP $>5 \mathrm{mg} / \mathrm{l}$, only two cases met criteria for Fe-deficiency anaemia.

\section{Infectious morbidity}

We found no difference in mortality or the incidence of infectious morbidities (diarrhoea, respiratory illnesses, pneumonia or malaria) between groups. Based on weekly symptom recall, in the cereal group, $44 \%$ of infants experienced an infectious morbidity, compared with $66 \%$ in the control group $(P=0 \cdot 22)$.

\section{Discussion}

In the present study, we evaluated the potential benefits of a cereal made with caterpillars and used as a supplement to complementary feedings in infants between 6 and 18 months of age. Caterpillars were used as a locally available option for an animal-source food. We hypothesized that the addition of this micronutrient-rich cereal would reduce the high endemic rate of stunting at 18 months. Compared with the usual diet, supplementation with caterpillar cereal did not reduce the prevalence of stunting at 18 months or improve linear growth velocity. However, infants in the cereal group had higher Hb concentration and fewer were anaemic.

Previous studies examining the effects of micronutrient supplementation on growth have had variable results. Some have demonstrated a beneficial role, particularly in Africa, where fortified foods have improved growth,
Fe and vitamin A status ${ }^{(24-26)}$. However, other studies have shown no difference in linear growth among infants who were supplemented with micronutrients from 6 to 18 months ${ }^{(27-31)}$. These studies have heterogeneous baseline participant populations, varying measures of anthropometry, various timing of interventions and many lack appropriate control groups ${ }^{(7,32)}$. We speculated that the lack of apparent benefit of multi-nutrient enriched diets in some studies resulted from a lack of a proper control; that is, a group fed the usual diet that is associated with stunting. For example, in a recent multi-site study including the DRC, the prevalence of stunting increased between 6 and 18 months of age among infants in four low-income countries despite being fed either beef or micronutrient-rich cereal ${ }^{(30)}$. In that study, there was no control group consuming the usual nutrient-deficient diet, so it was unclear if a reduction would have been observed had the intervention been compared with the usual diet. In order to investigate this possibility we included a control in our study design, thereby comparing a supplemental complementary food with the usual plant-based Congolese diet, but still found no effect of supplementation of the usual diet on linear growth measures at 18 months. In fact, the prevalence of stunting in both of our study groups was very similar to the prevalence observed in the multisite trial. These observations suggest that stunting is not solely attributable to dietary deficiencies of micronutrients during the period of complementary feeding and therefore not modifiable simply by increasing the nutrient content of complementary foods.

We speculate that the higher Hb levels and lower prevalence of anaemia in the cereal group at 18 months resulted from an improvement in Fe-deficiency anaemia among the group eating caterpillar cereal. However, ferritin concentration, an indicator of Fe stores, was higher in the control group. Higher ferritin concentration in the control group might simply be indicative of a higher burden of infection or inflammation in this group. We used CRP, another acute-phase reactant, to estimate the burden of inflammation in our cohort, and observed a high 
proportion of infants in both groups with elevated CRP concentration. According to our a priori definition of $\mathrm{Fe}$ deficiency, eliminating these infants from analyses resulted in a sample size too small to draw meaningful conclusions, and therefore we cannot determine the cause of the effect of cereal consumption on Fe-deficiency anaemia. Differences in the prevalence of anaemia could also be attributed to differences in other dietary or intrinsic factors such as vitamin $\mathrm{A}, \mathrm{Cu}, \mathrm{B}_{12}$ or folate deficient states, infection, chronic disease or haemoglobinopathies. The effect of caterpillar cereal on anaemia should be investigated in a larger trial.

We observed a high percentage of children (36\%) stunted at 6 months. Causes of stunting at this age may include preconceptional and gestational factors or inadequate nutrient intake, utilization or absorption, the latter of which may be caused by infections from ingested pathogens. Because birth lengths were not available on our cohort of participants, we cannot be certain that a significant portion were not stunted at birth due to preconceptional or gestational factors. The contribution of gestational factors to early infant stunting remains a subject of interest and investigation ${ }^{(33)}$.

The present study has limitations based on design and other practical issues. Because infants were enrolled at 5 months of age, we relied on maternal report of birth weight, which limited our ability to accurately evaluate this measure. It is unlikely that inaccurate birth weights had an effect on the outcome of the trial since similar numbers of infants were stunted in each group at the time of enrolment. Although we randomized communities based on baseline prevalence of stunting at 18 months of age, there could have been other baseline differences between communities that influenced infant health and growth. These differences might include the availability of a clean water source, basic sanitation devices or other hygiene conditions that were not evaluated in the course of the study. We lost an undesirably high percentage of infants to follow-up because many of the participants relocated and therefore outcome data were incomplete. Because there were no significant differences between the group that completed the study and those participants who were lost to follow-up, it does not appear that the loss of data introduced bias into the results, but it might have resulted in a sample that was insufficiently powered to detect modest differences in the prevalence of stunting. Furthermore, a high burden of inflammation among our population limited our ability to completely assess the mechanism of improvements in anaemia. Due to study design, we did not collect the prevalence of anaemia at enrolment. Because baseline prevalence of anaemia was not measured, we are unable to determine the magnitude of effect the caterpillar cereal had on anaemia.

The study is unique because we evaluated a locally available food source for infant feeding. This cereal has been shown to be acceptable to mothers and infants ${ }^{(14)}$.
Our cereal utilized insects, a rich source of $\mathrm{Zn}$ and protein, as an alternative to other animal-source foods ${ }^{(34)}$. Although we did not demonstrate a beneficial effect from supplementing complementary feeding with caterpillar cereal on linear growth, insects are a promising food source for people in food-insecure areas ${ }^{(35,36)}$. It is possible that improving the quality of complementary foods is beneficial if other growth-limiting pathologies are prevented.

The present trial adds valuable information regarding the timing of childhood stunting. Because we were unable to modify the prevalence of stunting through the provision of micronutrient-rich cereal after 6 months, it seems likely that factors that pre-date this age influence growth throughout infancy and early childhood. Future investigations should include a focus on causes, prevention and treatment of growth failure prior to 6 months of age. Given the high disease burden among infants in this impoverished rural area, the role of conditions that impair nutrient absorption and utilization appears to be a potentially fruitful area of investigation.

\section{Acknowledgements}

Financial support: This work was supported by the Bill \& Melinda Gates Foundation to FHI 360, through the Alive \& Thrive Small Grants Program managed by the University of California at Davis and the Thrasher Research Fund. The funders had no role in the design, analysis or writing of this article. Conflict of interest: None. Authorship: M.B., A.L., A.T. and C.B. designed the research; A.L. and J.G. conducted the research; K.-K.K. provided essential materials; K.C. and D.W. performed the statistical analysis; M.B. and C.B. wrote the paper; M.B. had primary responsibility for final content; all authors read and approved the final manuscript. Ethics of buman subject participation: Institutional Review Boards at the University of North Carolina and the Kinshasa School of Public Health approved the study, which is registered at ClinicalTrials.gov (NCT01282788).

\section{References}

1. Bhutta ZA, Das JK, Rizvi A et al. (2013) Evidence-based interventions for improvement of maternal and child nutrition: what can be done and at what cost? Lancet $\mathbf{3 8 2}$, 452-477.

2. Black RE, Victora CG, Walker SP et al. (2013) Maternal and child undernutrition and overweight in low-income and middle-income countries. Lancet 382, 427-451.

3. Black RE, Allen LH, Bhutta ZA et al. (2008) Maternal and child undernutrition: global and regional exposures and health consequences. Lancet 371, 243-260.

4. Bhutta ZA, Ahmed T, Black RE et al. (2008) What works? Interventions for maternal and child undernutrition and survival. Lancet 371, 417-440.

5. Victora CG, Adair L, Fall C et al. (2008) Maternal and child undernutrition: consequences for adult health and human capital. Lancet 371, 340-357. 
6. Ministry of Planning, Ministry of Health \& Macro International, Inc (2007) Congo Democratic Republic: Standard DHS, 2007. Kinshasa and Calverton, MD: Ministry of Planning, Ministry of Health and Macro International, Inc.

7. Dewey KG \& Adu-Afarwuah S (2008) Systematic review of the efficacy and effectiveness of complementary feeding interventions in developing countries. Matern Child Nutr $\mathbf{4}$, Suppl. 1, 24-85.

8. Butte NF, Lopes-Alarcon MG \& Garza C (2002) Nutrient Adequacy of Exclusive Breastfeeding for the Term Infant during the First Six Months of Life. Geneva: WHO.

9. Hambidge KM \& Krebs NF (2007) Zinc deficiency: a special challenge. J Nutr 137, 1101-1105.

10. World Health Organization (1998) Complementary Feeding of Young Children in Developing Countries: A Review of Current Scientific Knowledge. Geneva: WHO.

11. Dewey K (2003) Guiding Principles for Complementary Feeding of the Breastfed Child. Washington, DC: PAHO/ WHO.

12. Balinga M, Monzambe Mapunzu P, Mussa J-P et al. (2004) Contribution des insectes de la forêt à la sécurité alimentaire. L'exemple des chenilles d'Afrique Centrale. Programme des Produits Forestiers Non Ligneux, Document de Travail no. 1. Rome: FAO.

13. Cordain L, Miller JB, Eaton SB et al. (2000) Plant-animal subsistence ratios and macronutrient energy estimations in worldwide hunter-gatherer diets. Am J Clin Nutr 71, 682-692.

14. Bauserman M, Lokangaka A, Kodondi KK et al. (2013) Caterpillar cereal as a potential complementary feeding product for infants and young children: nutritional content and acceptability. Matern Child Nutr (Epublication ahead of print version).

15. Sawadogo PS, Martin-Prevel Y, Savy M et al. (2006) An infant and child feeding index is associated with the nutritional status of 6- to 23-month-old children in rural Burkina Faso. J Nutr 136, 656-663.

16. Ruel MT \& Menon P (2002) Child feeding practices are associated with child nutritional status in Latin America: innovative uses of the demographic and health surveys. J Nutr 132, 1180-1187.

17. World Health Organization (2001) Iron Deficiency Anaemia Assessment, Prevention, and Control. Geneva: WHO.

18. Miles LE, Lipschitz DA, Bieber CP et al. (1974) Measurement of serum ferritin by a 2 -site immunoradiometric assay. Anal Biochem 61, 209-224.

19. Alfrey CP (1978) Serum ferritin assay. CRC Crit Rev Clin Lab Sci 9, 179-208.

20. Erhardt JG, Estes JE, Pfeiffer CM et al. (2004) Combined measurement of ferritin, soluble transferrin receptor, retinol binding protein, and C-reactive protein by an inexpensive, sensitive, and simple sandwich enzyme-linked immunosorbent assay technique. J Nutr 134, 3127-3132.

21. Cook JD, Flowers CH \& Skikne BS (2003) The quantitative assessment of body iron. Blood 101, 3359-3364.

22. Thurnham DI, McCabe LD, Haldar S et al. (2010) Adjusting plasma ferritin concentrations to remove the effects of subclinical inflammation in the assessment of iron deficiency: a meta-analysis. Am J Clin Nutr 92, 546-555.
23. World Health Organization (2006) WHO Child Growth Standards based on length/height, weight and age. Acta Paediatr Suppl 450, 76-85.

24. Lartey A, Manu A, Brown KH et al. (1999) A randomized, community-based trial of the effects of improved, centrally processed complementary foods on growth and micronutrient status of Ghanaian infants from 6 to 12 mo of age. Am J Clin Nutr 70, 391-404.

25. Adu-Afarwuah S, Lartey A, Brown KH et al. (2007) Randomized comparison of 3 types of micronutrient supplements for home fortification of complementary foods in Ghana: effects on growth and motor development. Am J Clin Nutr 86, 412-420.

26. Phuka JC, Maleta K, Thakwalakwa C et al. (2009) Postintervention growth of Malawian children who received 12-mo dietary complementation with a lipid-based nutrient supplement or maize-soy flour. Am J Clin Nutr 89, 382-390.

27. Bisimwa G, Owino VO, Bahwere P et al. (2012) Randomized controlled trial of the effectiveness of a soybeanmaize-sorghum-based ready-to-use complementary food paste on infant growth in South Kivu, Democratic Republic of Congo. Am J Clin Nutr 95, 1157-1164.

28. Sguassero Y, de Onis M \& Carroli G (2005) Communitybased supplementary feeding for promoting the growth of young children in developing countries. Cochrane Database Syst Rev issue 4, CD005039.

29. Giovannini M, Sala D, Usuelli M et al. (2006) Double-blind, placebo-controlled trial comparing effects of supplementation with two different combinations of micronutrients delivered as sprinkles on growth, anemia, and iron deficiency in cambodian infants. $J$ Pediatr Gastroenterol Nutr 42, 306-312.

30. Krebs NF, Mazariegos M, Chomba E et al. (2012) Randomized controlled trial of meat compared with multimicronutrient-fortified cereal in infants and toddlers with high stunting rates in diverse settings. Am J Clin Nutr 96, 840-847.

31. Chilenje Infant Growth, Nutrition and Infection (CIGNIS) Study Team (2010) Micronutrient fortification to improve growth and health of maternally HIV-unexposed and exposed Zambian infants: a randomised controlled trial. PLoS One 5, e11165.

32. Sguassero Y, de Onis M, Bonotti AM et al. (2012) Community-based supplementary feeding for promoting the growth of children under five years of age in low and middle income countries. Cochrane Database Syst Rev $\mathbf{6}$, CD005039.

33. Prentice AM, Ward KA, Goldberg GR et al. (2013) Critical windows for nutritional interventions against stunting. Am J Clin Nutr 97, 911-918.

34. Kodondi KK, Leclercq M \& Gaudin-Harding F (1987) Vitamin estimations of three edible species of Attacidae caterpillars from Zaire. Int J Vitam Nutr Res 57, 333-334.

35. Latham P (2005) Edible Caterpilars and their Food Plants in Bas-Congo Province, Democratic Republic of Congo, 2nd ed. London: UK Department for International Development.

36. van Huis A, Van Itterbeeck J, Klunder H et al. (2013) Edible Insects: Future Prospects for Food and Feed Security. Rome: FAO 